\title{
CURRICULUM DESIGN AS AN ENABLER OF STUDENT INVOLVEMENT AND SUCCESS IN HIGHER EDUCATION
}

\author{
H. M. van Zyl* \\ Design Section \\ e-mail: rvzyl@vegaschool.com / https://orcid.org/0000-0002-7159-2766
}

\author{
Y. Burger* \\ Graphic Design Programme \\ e-mail: yolandibur@gmail.com / https://orcid.org/0000-0002-5121-9497
}

\author{
L. Carstens* \\ Creative Brand Communication \\ e-mail: Icarstens@vegaschool.com / https://orcid.org/0000-0001-9994-7912
}

\author{
M. Geyser* \\ Interior Design \\ e-mail: mgeyser@vegaschool.com / https://orcid.org/0000-0003-3247-4895
}

${ }^{*}$ The Independent Institute of Education

Vega School

Pretoria, South Africa

\section{ABSTRACT}

Quality assurance, promotion, and the success of students are core drivers in Higher Education. Students shifted from being receivers in the knowledge transfer process of Higher Education to active co-producers in the learning process, which makes students more involved in the quality assurance process today than they were in the past. This shift requires curriculum developers of programmes to not only understand the nature of the change in the students' role in Higher Education but also to anticipate future changes in their role. The Mode 1, Mode 2 and Mode 3 models of knowledge production are useful systems to help curriculum designers understand this daunting task. This research conducts a theoretical exploration into students' shift in knowledge production as they engage with the curriculum in higher education, which explores the different modes of knowledge production. The exploratory research includes practical curriculum examples that highlight the changes in the structures of control, characteristics, and practicalities of the different modes, changes in assessment strategies, changes in teacher-student relationships, and the inclusion of other role-players such as industry and society. The first mode of knowledge production is a disciplinary and homogeneity model, with the second mode shifting to a transdisciplinary, heterogeneous, transient, and more systemic model which includes industry stakeholders, with a permeable boundary. The third mode of knowledge production is situated in 
the fourth industrial revolution space and looks at the combined future of science, knowledge, and technology.

Keywords: modes of knowledge production, quality assurance, student involvement, systemic integration, futures

\section{INTRODUCTION}

This article is based on a paper delivered at the Council on Higher Education's (CHE) 2020 Quality Promotion Conference that focused on the changing role of students' involvement in quality promotion in Higher Education Institutions in South Africa. Students today are active co-producers of knowledge in the learning process, rather than passive receivers as in the past. As a result, they have become active participants in matters such as the quality of their own learning. Curriculum developers, therefore, need to understand the changing nature of students' role in Higher Education now and for the future. The Mode 1, 2, and 3 models of knowledge production provide a useful theoretical framework that can help guide curriculum developers frame their thinking of what a curriculum might consist of. This article explores some of the changes in the structures of control, characteristics, and practicalities of the different modes of knowledge production, changes in the dynamics of teaching and learning, power shift dynamics in teacher-student relationships, and the inclusion of other role-players such as industry and society. The second part of the article is a reflexive description of the co-design approach taken by a team of curriculum and programme developers in the fields of graphic, digital, and interior design at a private institute of Higher Education in South Africa.

\section{SHIFTS IN KNOWLEDGE PRODUCTION MODES}

Mode 1 refers to traditional knowledge production processes that are homogenous and hierarchical, hegemonic, and internally driven through the needs of the discipline (Nowotny, Scott and Gibbons 2003, 179; Sandstrom 2014, 19). An example would be the "ivory tower" view of a university, where an autonomous scientist or a group of scientists with homogeneous backgrounds work on disciplinary problems and quality is controlled by a few experts (Nowotny et al. 2003, 179; Sandstrom 2014, 19). The traditional Mode 1 university, with its roots in the Renaissance, regarded theory highly but only tolerated practice (Buchanan 2001, 5). The "making" associated with the design disciplines was not regarded as a subject of learning in the liberal arts, with fine arts and architecture being exceptions (Buchanan 2001, 5). Design as a discipline was only added to universities early in the first half of the twentieth century as "new" learning (Buchanan 2001, 6) and in South Africa much later.

Mode 1 is challenged by Mode 2 knowledge production, a concept coined in 1994 by 
Gibbons, Limoges, Nowotny, Schwartzman, Scott, and Trow in the landmark publication: The New Production of Knowledge: The Dynamics of Science and Research in Contemporary Societies (Hessels and Van Lente 2010, 65). Mode 2 is regarded as knowledge produced through solving problems and is intrinsically heterogeneous. As a socially distributed system, Mode 2 is diverse, globalised, context- and application-oriented, and trans-disciplinary as opposed to inter- or multi-disciplinary based on pre-existing disciplinary knowledge (Nowotny et al. 2003, 179, 186; Sandstrom 2014, 19). An example would be a network of university partners with different disciplinary backgrounds collaborating on an application-oriented problem with other stakeholders from industry or other public institutions. Diverse participants and not only university experts participate in quality control (Sandstrom 2014, 19).

Mode 2 legitimises newer disciplines such as management and links science with innovation (Nowotny et al. 2003, 179). Mode 2 is also characterised by the shift from elite to mass higher education and the democratisation of higher education, where knowledge is widely and socially distributed (Nowotny et al. 2003, 188). In the research space, social and economic needs became the driver (Kraak 2002, 13). Mode 2 allows for people from industry and stakeholders from other backgrounds to take part in the education processes and display the characteristics of a network with a permeable boundary.

Mode 2, despite some shortcomings and critique, contributed to changes in policy and education, also in South Africa (Kraak 2002, 9 - 33). Central to this new mode was the renewed focus of globalisation in a democratic South Africa and the democratising and massification of access in South Africa with the focus on the development of professionally skilled citizens. The economically driven open system created the need for education in professional and "paraprofessional" fields (Kraak 2002, 13). A field such as design and its subfields such as communication and interior design moved into Universities and Universities of Technology and broke the tradition of being part of the more established fine arts and architecture disciplines.

Mode 2 shifted to hybrid knowledge production that, unlike Mode 1, includes both discipline (vertical) and work/community based (horizontal) structures (Kraak 2002, 13). Work-based knowledge and experiential competencies became part of the curricula in South Africa (Kraak 2002, 13) and globally in design education (Sanders 2017, 4,6). These developments took place during a time of rapid technological change and development, hence the increase in programme offerings, especially in the fields of continuing and professional education (Kraak 2002, 13). At that time, the South African Higher Education was being restructured into its current structure (Asmal 2002, 1-3).

As part of Mode 2 thinking and the drive for massification, access courses were developed 
to allow access for the non-traditional student. One such example was the Positive Response in Design Education (PRIDE) programme in 1990, initiated by ML Sultan Technikon (later integrated with Technicon Natal to form Durban University of Technology). A one-year bridging programme in design was presented for students from townships and informal settlements around Durban and funded by industry partners such as the De Beers Anglo American Chairman's Fund, the advertising agency Ogilvy, Mather, Rightford, Searle-Tripp, and Makin. The purpose of the industry funded course was to stimulate the development of black designers for the changing advertising industry (Sutherland 2004, 57).

In Mode 2 subject-based teaching shifted to student-centred learning which resulted in teachers becoming facilitators of knowledge rather than the experts (Kraak 2002, 16). Quality and accountability also shifted during this time with various stakeholders taking accountability (Nowotny et al. 2003, 3). The programme guidelines of the South African Qualifications Authority (SAQA 2000, 18-19) lists several critical cross-field outcomes including the development of students who are responsible for their responses and activities as well as being local, national, and globally responsible citizens. Since students need to be accountable, they should participate in the conversations that impact them such as quality.

Some reasons for the shift from Mode 1 to Mode 2 were the need for adaptability in academic institutions, new roles, new market needs, new technologies, and the need for new "institutions" to demonstrate their uniqueness and competitiveness (Kraak 2002, 14-16). The higher education system in South Africa today still reflects many of the pragmatic characteristics of Mode 2 thinking (e.g. that it is modular, credit-based, and outcome driven that allows for transfer and mobility, a unified national qualification system, trans-departmental schools rather than departments and include workplace integrated learning in different forms) (Kraak 2002, 14-16). However, Kraak $(2002,17)$ points out the tension between the need to innovate and differentiate, and the creation of a single regulatory system of control. He emphasises the need for this regulatory environment to align education in an orderly fashion with diversity, responsiveness, and with key “economic, social and cultural goals” (Kraak 2002, 17).

Even though some scholars saw the "Modes" debate as somewhat unscientific, or that many saw Mode 2 as sufficient (Sandstrom 2014, 16) the debate continued with Mode 3 being described as a way of trying to make sense of new challenges and opportunities. Mode 3 is seen as "dynamic and unsettled" (Sandstrom 2014, 16). Sandstrom $(2014,17)$ points out the complexity of Mode 3 as it deals with broad higher education transformation in many aspects such as local, regional, and global levels, marketisation of knowledge and practical issues such as teaching practices, university planning/administration, and curriculum development, socio- 
economic and technological shifts.

In Mode 3 attention shifts to students' needs and desires, and reflexive knowledge about the contribution "I/we" can make (Sandstrom 2014, 20). Sandstrom $(2014,20)$ refers to this as the shift away from positivist pre-ordained models. Students are now seen as individuals who bring with them their own realities and tacit knowledge. Sandstrom $(2014,23)$ explains the need for Mode 3 education to not only produce workers but also "human beings" or "global citizens" (Sandstrom 2014, 25). Sandstrom $(2014,35)$ agrees with Finn ... "to become a critical creative and educated student (or teacher) one should not only be able to hear "the voice of knowing', 'the voice of doing' and 'the voice of control and marketing', but that is also the professional epistemological voice, the practical and technological voice and the voice of the Systems. One should indeed also hear 'the voice of being', that is the ontological voice".

The third mode of knowledge production is situated in the fourth industrial revolution space and looks at the combined future of science, knowledge, and technology, a space characterised on the one hand by unthinkable access to knowledge on the web, but still for many in the developing countries such as South Africa, hampered by a lack of resources. In Figure 1 the flow from Modes 1 to 3 is depicted, with the Modes not replacing each other, but building on each other.

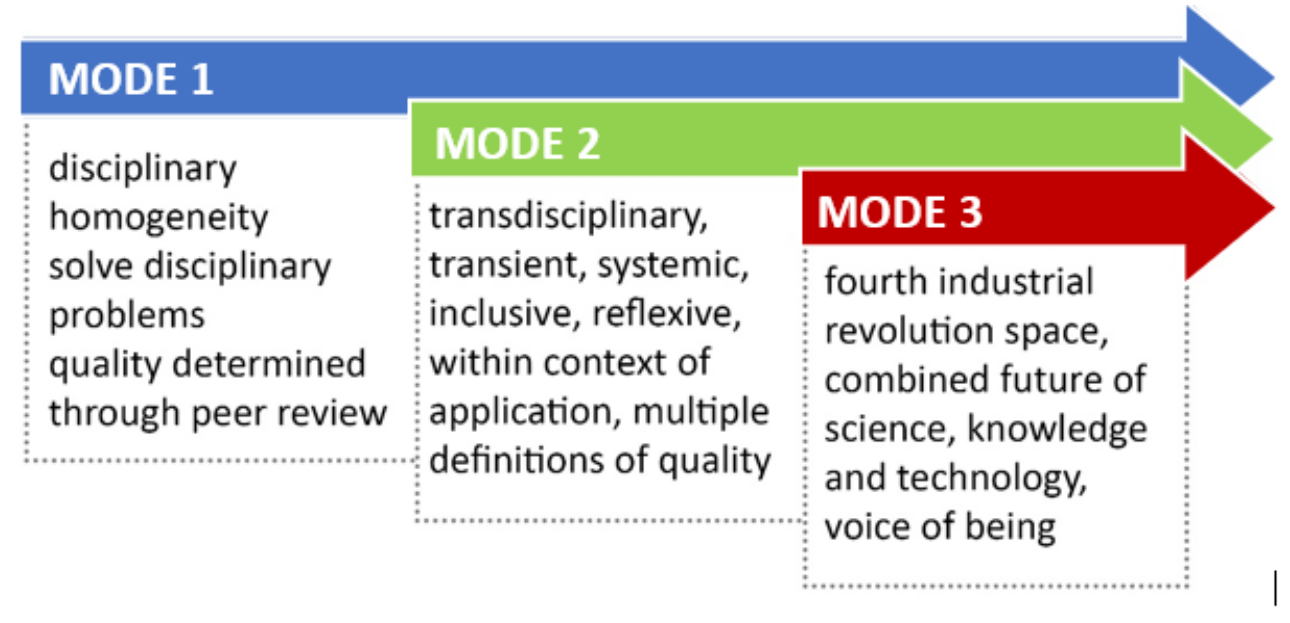

Figure 1: Visualising Modes 1, 2, and 3.

\section{WHICH WAY FORWARD FOR CURRICULUM DEVELOPERS?}

Curriculum developers are challenged with a complex and ever-changing education landscape. They can neither discard Mode 1 knowledge nor ignore Mode 2 requirements and needs from industry. However, a focus only on these requirements and ignoring Mode 3 shifts will be limiting, short-sighted and will fail to respond to current shifts in education and specifically within the discipline of design, that is strongly aligned with Mode 3 multilevel systems of knowledge and systemic networks with an innovation perspective (Carayannis, Campbell and 
Rehman 2016, 17; Sanders 2017, 6-7). This need for innovation is also extended to education providers, not only for our students to be able to enter this new world but also for the curriculum designers who need to innovate and differentiate offerings. The question here is what we as curriculum designers can learn from Mode 3 thinking and doing, how we can apply this in our curriculum design and development process, and then, lastly, what the impact could be on quality assurance and student engagement.

Curriculum developers can be catalytic agents in making higher education qualifications more responsive to contemporary societal and economic needs and instrumental in the production of knowledge that spans beyond disciplinary boundaries (Mahabeer 2018, 2). To prepare students for the future workforce and the fourth industrial revolution (4IR) graduates need to be "significantly different from those of yester-year" (Xing, Marwala and Marwala 2018, 178, 179). Curriculum developers therefore also need to find ways of developing curricula that are responsive and adaptive to a fast-changing environment, requirements, and contents.

The next section explores the approach and process of co-design as part of curriculum development as used by a team of developers at a private higher education institute in South Africa. Co-design during the curriculum design process offers a uniquely suitable agile vehicle for navigating the shifts from Mode 1 to 3, and the crossroads between education and practice, disciplinary specialisation and trans-disciplinary knowledge (Sanders 2017, 3-15).

\section{CO-DESIGN CURRICULA FOR THE FUTURE}

Design processes are iterative and structured, as can be seen in the Double-Diamond Design Process depicted below (Figure 2) (Ball 2019, s.p.). The Double-Diamond Design Process comprises the phases of discovery, definition, development, and delivery (Figure 2) and the model provides a practical understanding of the flow and structure for any design process whether it is an industrial design project, the design of a building or in this case the design of syllabi and student experience. The Double-Diamond Design Process allows for the participation of stakeholders throughout the process in the form of either feedback loops or more generative participation as co-designers, or active participants.

Co-design is a well-established approach that is widely used in a variety of fields including change management, community development, and design practice and is rooted in the guiding principles of equalising power relations, democratic practices, context-based actions, and mutual learning (Drain and Sanders 2019, 39). 


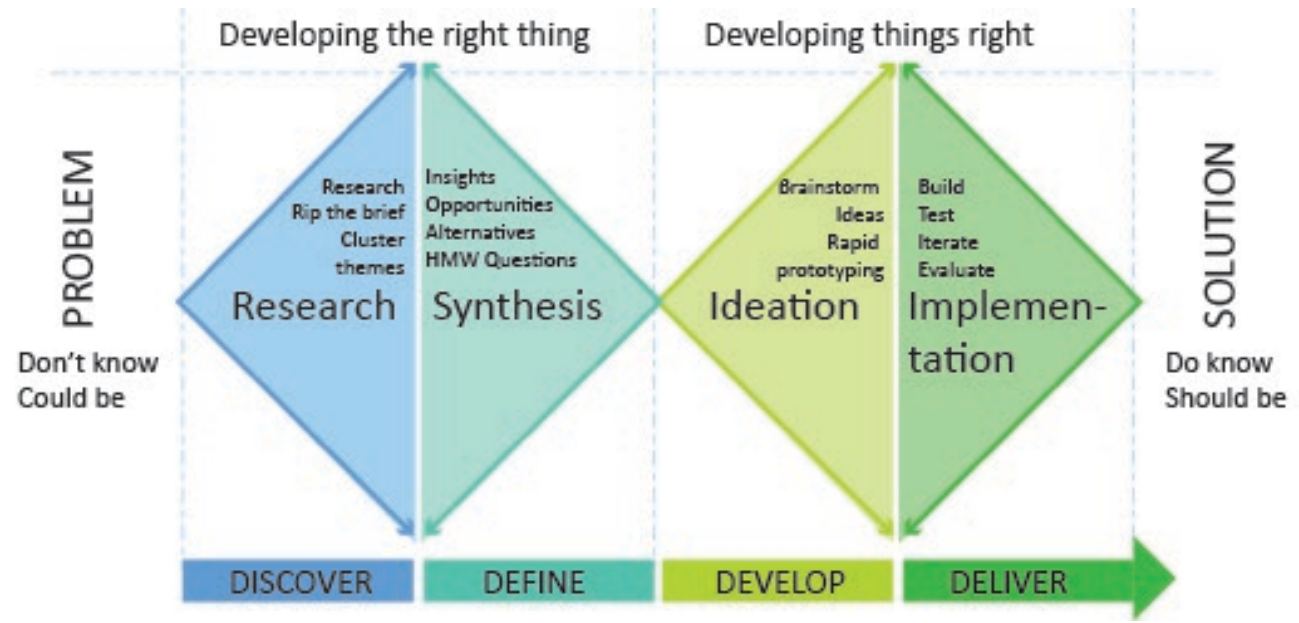

Figure 2: The Double-Diamond Design Process (Ball 2019, s.p.).

During the discovery phase of design projects, such as developing curricula, challenges and opportunities are explored and research is conducted to make sense of the context within which a problem exists, and to understand the values and expectations of stakeholders. Sense-making turns into abduction and multiple perspectives and diverse knowledge are synthesised into a more defined vision of a better alternative.

Co-design approaches are especially valuable during these initial stages. Co-design here focuses on needs and aspirations and aims to create a dialogue that may uncover what some may not yet perceive as a need or that participants do not yet understand as a problem, or know how to address (Sanders and Simons 2009, 3). Participants' role is to collectively make sense of what is and to negotiate a shared vision of a more ideal future (Sanders 2017, 5) making this not only a user-centred but also a human-centred approach.

During the later phases of the design process, such as the development stage and testing of solutions, ideas on how the more desired outcome might be achieved are generated, explored, developed, and tested, moving ever closer to a solution that reflects the desired outcome. As curricula exist in an ever-evolving environment, curriculum design is an ongoing process, constantly moving through different design phases (see Figure 2).

The design process never stands still, but is a continuation of ongoing iterations, just with different scope and scale (as depicted in Figure 3). This is also true for curriculum development, where courses must continually be adapted and adjusted to new developments.

There are different co-design tools and participatory techniques that can be used during the different stages of the design process. For example, structured participatory research tools such as search-conferences and generative workshops offer valuable insights from multiple perspectives during the early phases of the curriculum design process. The curriculum developer here shifts from curriculum designer to that of participation facilitator. Some tools 
and approaches used in this study are briefly outlined below.

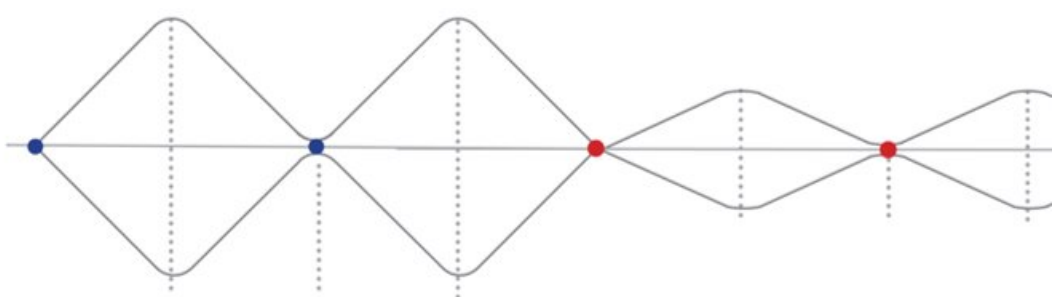

Figure 3: The Double-Diamond Design Process - ongoing iterations illustrated.

An example of a generative activity is where alumni (in this case a group of Honours students) were asked to redesign their first qualification. The results were presented to the class as an inclass activity and discussion and provided valuable insights in terms of the student experience, what students value, and consider relevant in a design curriculum. The class comprises alumni from different institutions, qualifications, and ages, some with industry experience and some without (see Figure 4). Insights from generative activities such as this are then compared and combined with information gained from other sources such as student focus groups, student feedback, and more formal alumni feedback, to get a broad view of student needs, expectations, and aspirations.

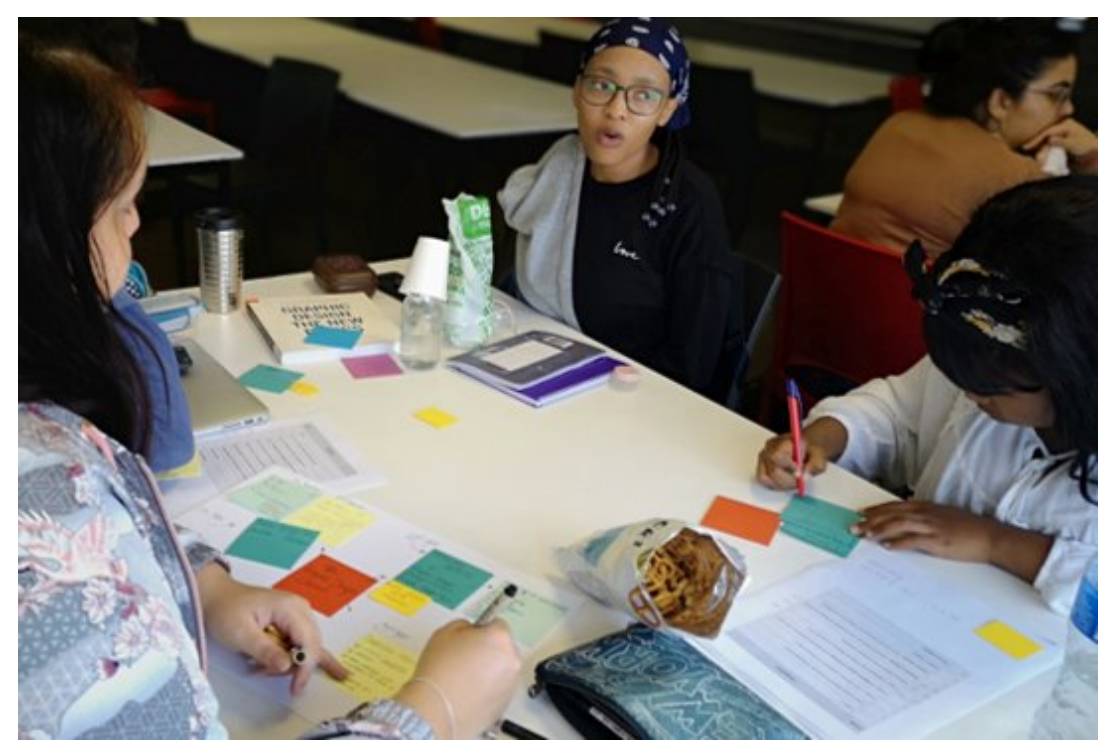

Figure 4: Honours students redesigning their first degree.

Participatory search conferences and generative workshops with lecturers and course designers from different disciplines and faculties allow participants to collectively explore options, debate, and agree on desired module outcomes. In Figure 5 such a generative workshop was conducted where the horizontal and vertical scaffolding of different qualifications, presented in 
different faculties, were interrogated, debated, and restructured. The purpose of this workshop (as part of a series of workshops) was to identify content gaps and/or content overlap across different modules and NQF levels, and specifically to identify opportunities for multidisciplinary and cross-disciplinary collaborative projects and simulations. Proposed plans from these workshops were evaluated against parameters such as the Level Descriptors for the National Qualifications Framework and institutional policies and frameworks for quality assurance.

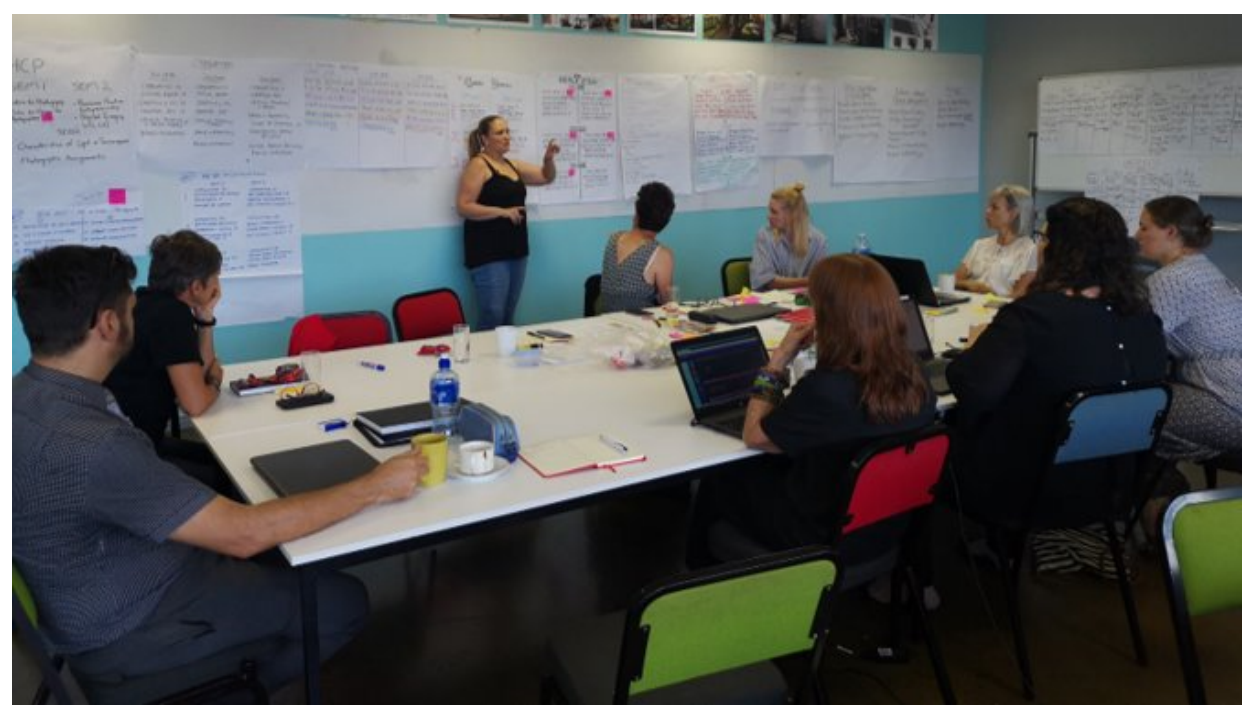

Figure 5: Programme managers and lecturers' planning sessions for different degrees across disciplines and faculties.

Insights and information gathered during these co-design activities are then further supplemented with information gathered from external participants, for example with institutions such as Innovation Hubs, Centres at other private or public Institutes of Higher Education, and local and international industry organisations. Further insight into industry requirements is drawn from feedback provided by employers who facilitate the different Work Integrated Learning (WIL) activities such as internships, real-life briefs, or immersions. Feedback here is especially useful in identifying areas where students exceed and/or fall short of industry expectations.

All decisions regarding the curriculum design are made collectively, informed by research, and based on evidence. The most valuable benefit of a co-design approach is the empowerment of participants and the subsequent development of a lively community of practice. Lecturers teaching into the new curricula furthermore share suggestions and ideas for classroom practices, assessment approaches, and content on a cloud-based collaborative platform. This platform has become a space for knowledge co-creation and innovation where lecturers and academic 
managers share and curate resources, debate new ideas and thoughts, and discuss experiences of what works well in the classroom and what does not. Lecturers feel empowered to share suggestions regarding the use of new technologies, alternative assessment approaches, and classroom activities, and academic managers, therefore, have access to constant and immediate feedback streams, allowing a flexible and agile approach to content development and teaching and learning approaches.

This integrated design approach to curriculum development assists not only with Mode 1 and Mode 2 curriculum development where the curriculum is based on theoretical principles and industry requirements but also caters for Mode 3 shifts in the inclusion of generative processes for different voices (some cognitive, some tacit). Students benefit from the process as they are actively participating in the design of their own curriculum, and projects are aligned with new realities and students' needs, not only Mode 1 (theory), Mode 2 (workplace related practical knowledge) but the participatory new space of Mode 3. Learning in design qualifications are mostly project-based, and a small selection of recent projects are presented here that show new thinking in the curriculum and the shift in modes towards more inclusive approaches.

\section{CASE-STUDY 1: GLOBAL BRAND GOES LOCAL}

Samsung South Africa collaborated with multidisciplinary student teams to create local narratives for a global Samsung audience. Students participated in an eight-hour conceptual design challenge. They had to create mobile themes with a local South African flavour by interpreting their realities, experiences, and tacit knowledge (cf. Sandstrom 2014, 20) of what they deem to be a local. Emerging themes from student projects included minibus-taxis, Proudly South African products, indigenous fauna and flora, and natural African beauty as possible local narratives. The variety of themes emerging from this project supports the individuality of the student team's interpretation of their reality, experiences, and tacit knowledge to visually portray what they regard as South African flavour. A conceptual design challenge promotes students' ability to rapidly prototype design solutions and develop their soft skills (e.g. timemanagement, self-organisation, visual and verbal communication, and teamwork). The development of soft skills is key to the holistic development of graduates as per the Critical Cross-Field Outcomes of SAQA (2000, 18-19).

This project is a good example of the control shift of knowledge value that takes place across the various modes of knowledge production. Firstly, the academic institution selected the best student projects for submission to Samsung South Africa. Secondly, the company selected the three best mobile designs which they then put forward for a public vote on social 
media. Thus, shifting the control from the company to civil society. Thirdly, the control returns to the students who won the competition since they now need to accept their achievement, reflect on their learning experience, and implement the knowledge gained from this experience into their knowledge frameworks.

\section{CASE-STUDY 2: OWN PASSION}

The Creative Conscience annual competition inspires and rewards creatives to apply their talents to socially valuable projects, promoting sustainability, freedom, social health, and wellbeing. A second-year Graphic Design student entered this competition as a side project which was outside of the planned curriculum. It is important to value individual student choices such as reported in this case-study to meet students' needs and desires, and the contribution they want to make to civil society ( $c f$. Sandstrom 2014, 20). His lecturer at that time motivated him to enter and provided him with the necessary support outside of normal teaching time.

The student was rewarded by the competition panel with an international Creative Conscience Award for his competition entry. He used his tacit knowledge and crafting skills learned through the curriculum to design a social campaign to promote mental health amongst his fellow students. The institution celebrated him for his courage and achievement by launching his social campaign nationally to support the contribution he wanted to make (i.e. to promote mental health amongst his fellow students). The contribution of his project extended beyond the student's initial planning since awareness was also raised amongst academic teaching staff and programme managers. The student reflected on his achievement with the following statement:

“... it is a great privilege to be part of this global movement and to be able to participate in inspiring people to change their lives for the better".

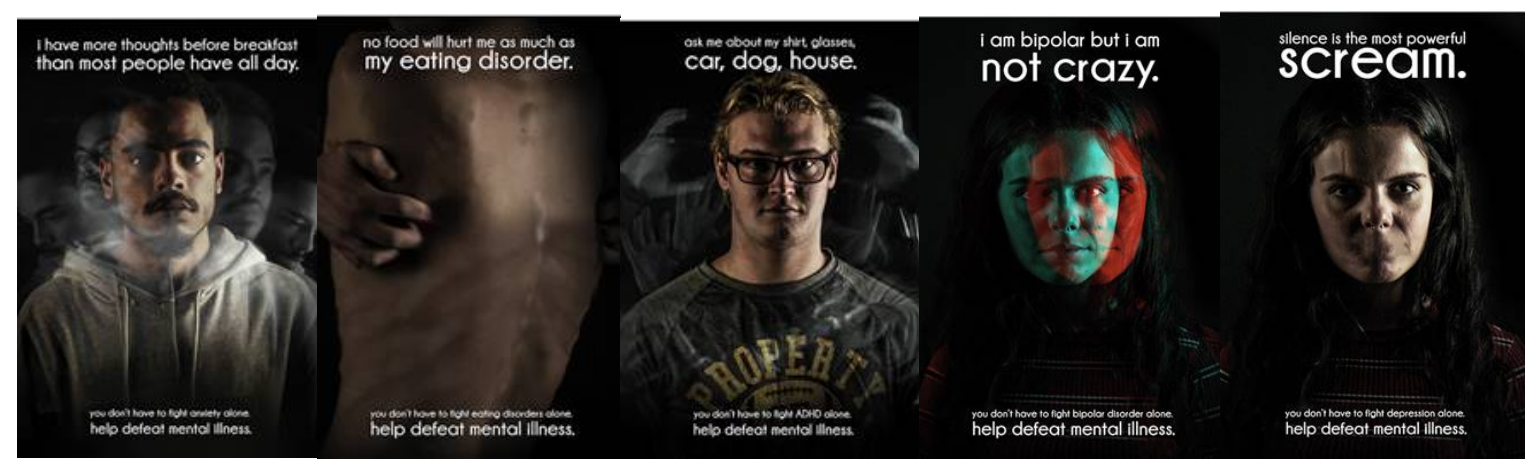

Figure 6: Example of a passion project (credit Marius du Toit). 


\section{CASE-STUDY 3: LOCAL COMMUNITY PROJECT}

The Interior Design curriculum includes a problem-based project where second- and third-year Interior Design students are required to work with a local community and provide a design service to a community that would not be able to afford these services otherwise. The students worked in teams and were required to develop concepts and relevant creative executions that address the key issues and challenges faced by the community. The client, a non-profit organisation in Winterveldt (Soshanghuve, Tshwane), provides basic services to vulnerable children (with emotional, physical, and/or social developmental needs) with the use of an early childhood development programme (for children from 0 to 6 years) and an after-school programme for children aged 7 to 18 . The students were tasked to provide energy-efficient and cost-effective design solutions to improve the childcare centre's current classroom facilities.

Students used their existing knowledge learned through the curriculum to create design solutions for the problems faced by this community, but they also had to rely on knowledge outside of the boundaries of what they know and to integrate the needs and insights of their users (who are the experts of their experience) to create compassionate and empathetic design solutions for the community. Students became aware that they have the knowledge and skills as interior designers to transform a community (therefore to become global citizens).

Knowledge production is extended into Mode 3 through reflective practice, as students were required to reflect on their learning experience, what they learned in their interaction with others and how awareness of their own skills and abilities changed through the design process. In addition, awareness was raised about the contribution "I/we" can make through reflection (reflexive knowledge) (Sandstrom 2014, 20).

\section{CASE-STUDY 4: OPEN COMMUNITY PROJECT}

The last semester of several programmes includes a passion project where students need to codesign a solution in the context of the 2030 Sustainable Development Goals with a local society/community. Students must define a challenge, conduct research through appropriate qualitative methods, write their own project outcomes, formulate own assessment criteria against which their solution will be measured, manage themselves and their project, and complete a self-assessment with reflection. Such a project promotes students' individual learning needs and gives them the freedom to select which contribution they want to make.

This project allows students to interact with the real world and combines disciplinary knowledge and knowledge outside of the boundaries of higher education teaching to solve realworld problems. IDEO's approach to Human-Centred design drives this project as a collaboration between academia and the community (IDEO s.a.). The first phase requires 


\section{Emmanuel}
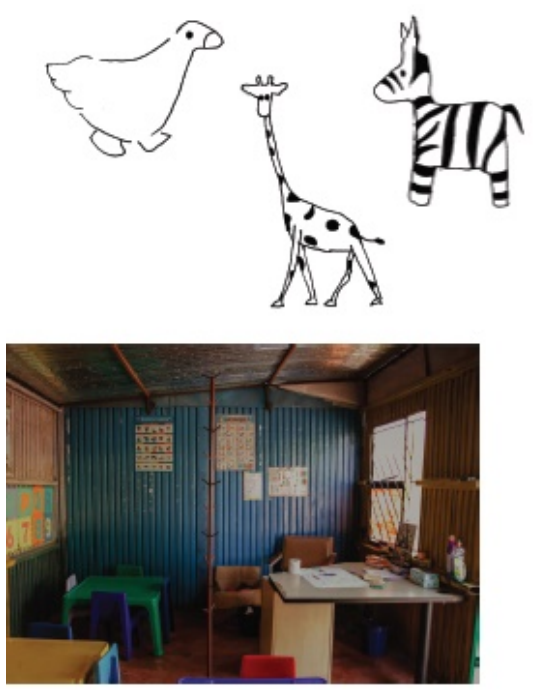

Initial Average Cost Estimation: $\pm R 2700.00$
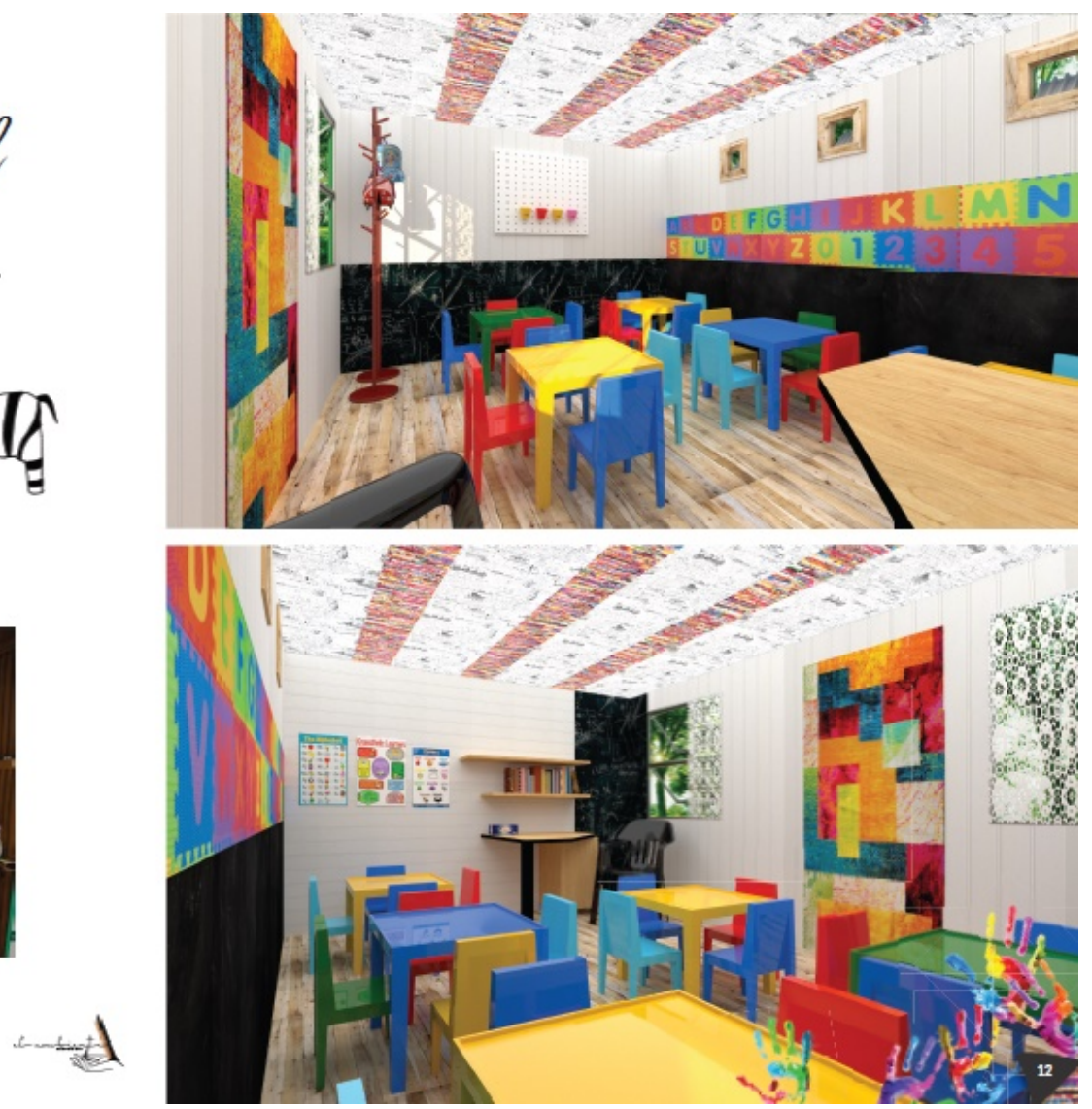

\section{Hannah}
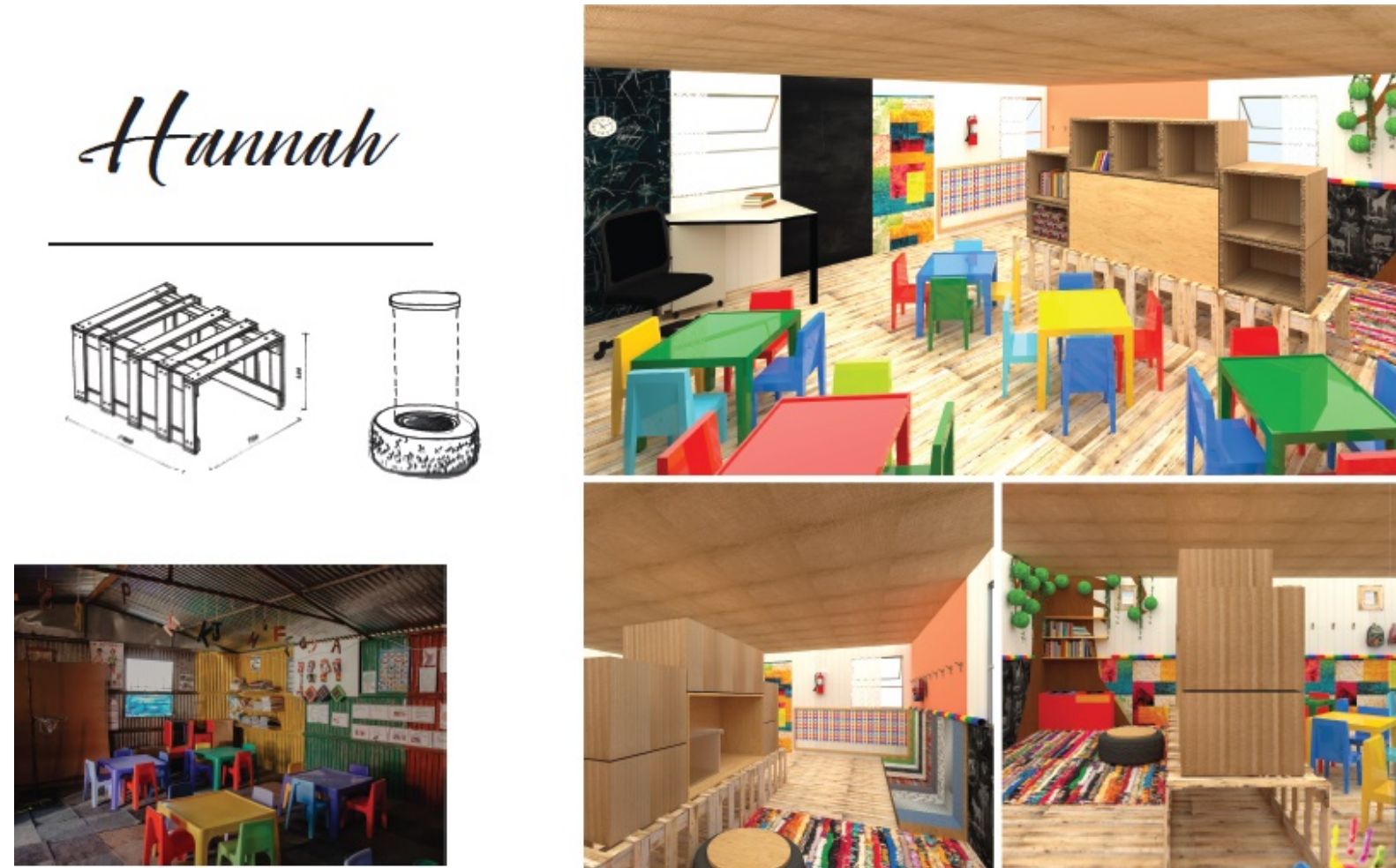

Initial Average Cost Estimation: $\pm R 4600.00$
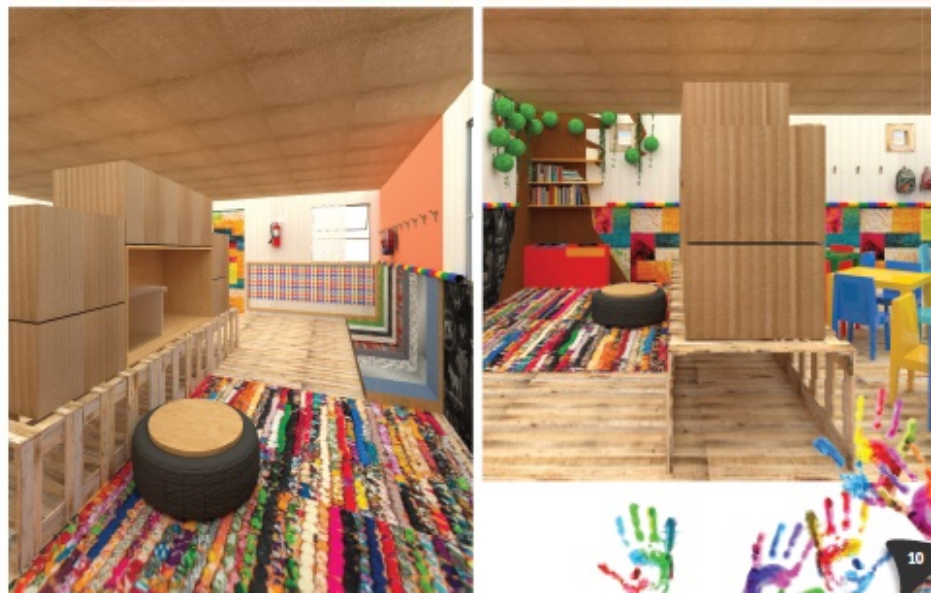

Figure 7: Examples of some of the Interior Design solutions for a non-profit organisation in Winterveldt. 
students to engage with the community to gain a true understating of their needs, hopes, and aspirations for the future through appropriate qualitative methods. The second phase consists of participatory Co-Design and/or Empathic Design to help students translate what they learned in the field (the first phase) into concrete solutions to their specific challenge. In the last phase, students need to transform their ideas and prototypes into solutions and plans that potentially can be implemented.

Through reflective practice, students become aware of the difference they can make, and the potential when they work "with" users and use co-design and empathic processes, shifting this type of learning to a Mode 3 experience. The community, peers, and teachers provide feedback on final concepts - therefore shifting control from Mode 1 to Mode 3.

\section{CONCLUDING REMARKS}

At this point in time we, as design educators and curriculum developers, need to reflect whether we are designing curricula that sufficiently promote the various modes of knowledge production and ensure that our students are co-designers of their own curriculum. Therefore, we acknowledge that there is room for growth towards fully embracing a Mode 3 approach which promotes our students as active participants in their own learning journey. Furthermore, we also face the reality that the future is unknown, therefore mindful of the fact that curricula must be versatile and flexible and promote the adaptability of students for future careers. The theoretical knowledge learned in Mode 1 may be soon forgotten, but the knowledge gained in Mode 2 and 3 promotes the development of lifelong learners and responsible citizens.

The ever-advancing technology industry creates space for designers to play and explore more with new technologies and approaches that are readily available (e.g. gamification, virtual reality, social media stories, projection mapping, holographic display and augmented reality). The closer we move to Mode 3 knowledge, the more engaged students become since they now have a valuable contribution to make beyond the classroom. Thus, the system of control shifts from the lecturer and institution to the stakeholders, civil society, and of course our students. The renowned \#FeesMustFall movement in South Africa highlights the need for our students to be heard and included in decisions such as quality promotion in their struggle to overcome the many access challenges they face (e.g. institutional, financial and cognitive access).

In conclusion, we need to design curricula for "real" people. This article reflects on shifting our thinking, and we fully recognise the need for further development and research As a result, we need to continuously aspire to improve our curriculum design process to make it more responsive, flexible, future geared, and inclusive of all stakeholders. 


\section{REFERENCES}

Asmal, K. 2002. The restructuring of the higher education system in South Africa. Pretoria: South African Government. https://www.gov.za/documents/restructuring-higher-education-systemsouth-africa-report-national-working-group (Accessed 1 May 2020).

Buchanan, R. 2001. Design research and the new learning. Design Issues 17(4): 3-23. https://doi.org/10.1162/07479360152681056 (Accessed 30 April 2020).

Ball, J. 2019. The double diamond: A universally accepted depiction of the design process. https://www.designcouncil.org.uk/news-opinion/double-diamond-universally-accepteddepiction-design-process (Accessed 26 May 2020).

Carayannis, E. G., D. F. J. Campbell and S. S. Rehman. 2016. Mode 3 knowledge production: systems and systems theory, clusters and networks. Journal of Innovation and Entrepreneurship 5: 17. https://doi.org/10.1186/s13731-016-0045-9 (Accessed 26 May 2020).

Drain, A. and E. B-N. Sanders. 2019. A collaboration system model for planning and evaluating participatory design projects. International Journal of Design 13(3): 39-52.

IDEO. s.a. Design Kit. https://www.designkit.org/methods (Accessed 26 May 2020).

Hessels, L. K. and H. Van Lente. 2010. The mixed blessing of Mode 2 knowledge production. Science, Technology \& Innovation Studies 6(1): 65-69.

Kraak, A. 2000. Changing modes: A brief overview of the "Mode 2" knowledge debate and its impact on South African policy formulation. In Changing modes: New knowledge production and its implications for higher education in South Africa, ed. A. Kraak, 9-33. Pretoria: Human Sciences Research Council.

Mahabeer, P. 2018. Curriculum decision-makers on decolonising the teacher education curriculum. South African Journal of Education 38(4): 1-13.

Nowotny, H., P. Scott and M. Gibbons. 2003. Introduction: "Mode 2" revisited: The new production of knowledge. Minerva 41: 179-194.

Sanders, E. B-N. and G. W. Simons. 2009. A social vision for value co-creation in design. http://www.timreview.ca/article/310 (Accessed 26 May 2020).

Sanders, E. B-N. 2017. Design research at the crossroads of education and practice. She-ji The Journal of Design Economics and Innovation 3(1): 3-15. https://doi.org/10.1016/j.sheji.2017.05.003 (Accessed 26 May 2020).

Sandstrom, G. 2014. Higher education and science for development: The historical and conceptual foundations of Mode 3. Knowledge Education Sciences and Society 5(1): 15-44.

SAQA see South African Qualifications Authority.

South African Qualifications Authority. 2000. The National Qualifications Framework and Curriculum Development. https://www.saqa.org.za/docs/pol/2000/curriculum_dev.pdf (Accessed 26 May 2020).

Sutherland, I. 2004. Paradigm shift: The challenge to graphic design education and professional practice in post-apartheid South Africa. Design Issues 20(2): 51-60. https://doi.org/10.1162/ 074793604871284 (Accessed 26 May 2020).

Xing, B., L. Marwala and T. Marwala. 2018. Adopt fast, adapt quick: Adaptive approaches in the South African context. In Higher education in the era of the Fourth Industrial Revolution, ed. N. W. Gleason, 171-206. Palgrave Macmillan, Singapore. https://doi.org/10.1007/978-981-13-0194-0_8 (Accessed 26 May 2020). 